\title{
Power Quality Inquiry for Grid Connected Solar Inverter
}

\author{
Tapas Kumar Mohapatra, Sujit Kumar Dash
}

\begin{abstract}
The projected paper presents the survey on load, $P V$ based system, and grid location, affected by the presence of harmonics. Nowadays Photovoltaic (PV) energy has been extensively attentive since it's fresh and infinite energy without creating pollution. An inverter is required to produce electrical energy from solar. One of the reason for unstable power system is an inverter which is a switching device. It is functioned to regulate the frequency of an $A C$ power as per requirement. On the other hand, it leads to distortion of waveforms produced by the introduction of that upset electronic devices which are employed to receive power. At that moment, it could create the incorrect functioning of electronic devices. The outcomes demonstrations that maximum grid's harmonics are influenced by the photovoltaic system and the load when the inverter is powered up to the rated value, for the meantime, harmonics present in the load be governed by on the category of load and the fractions of harmonics are compact. Analyzing, the effect of harmonics for three edges, we got to know that harmonics of photovoltaic based system barely have an consequence on load while the harmonics of grid are more exaggerated from load as compared to the $P V$ system
\end{abstract}

Index Terms- DG (Distributed-Generation), PV (Photovoltaic), Solar Inverter, THD (total harmonic distortion)

\section{INTRODUCTION}

Greatest amount of electricity generated by solar based energy is parted into 2 customs. Initial one is related to rooftop solar and that can be an inferior level of electricity production and may accomplish unexploited part on the rooftop for achieving advantages[1]. Less energy is produced by this configuration as compared to grid system, though when there exists numerous solar rooftops in the zone then it can make large amount of energy and cut back the electrical power consumption to the line of transmission. Solar farm is another one that might be a source of huge amount of electricity fabrication and produces vast energy. Meanwhile every form direct power to the line, consequently it's desired to regulate the quality of power and steadiness of power system transmission [2]. Concerning about quality of power, the prime issue is presence of harmonics that are produced by solar based system, consequently the produced power is going to be directed towards the demand within the zone. It might have an consequence on electrical or electronics tools and on system transmission if the system has additional harmonics [3].

Revised Manuscript Received on September 10, 2019.

Tapas Kumar Mohapatra, Dept. of Electrical Engineering, Siksha O Anusandhan Deemed to be University, Odisha, India. (Email:tapasmohapatra@soa.ac.in)

Sujit Kumar Dash, Dept. of Electrical \& Electronics Engineering, Siksha O Anusandhan Deemed to be University, Odisha, India.

(Email: sujitdash@soa.ac.in)

We have reviewed plurality of analysis papers in ground of harmonics based on the PV system and also studied the influences. Paper [4] introduced the forecasting of quasiresonance impedance network between the grid and DG inverters. Harmonic interaction is calculated between the grid and an obvious variety of DG inverters [5]. The projected harmonic detector by the use of 4th-ordered band pass filter, without the delay in phase can efficiently excerpt harmonic components[6].

A single-phase 2-level electric inverter with closed-form logical approximation of the resultant harmonic spectrum under the act of hysteresis current regulation is done. Artificial neural networks for harmonic elimination issue to acquire the angles of switching in an eleven-level full-bridge cascade electric inverter is powered via 5 fluctuating DC input sources[7]. It's examined that limits of the standard resonant current regulation operating under abnormal grid conditions and introduces an impact theme from 3-phase PV inverter. It is showed that a unique design of electric inverter current regulation that lessened lower order harmonics. The entire design had been valid with experimental results and smart agreement with theoretical analysis of the general system was determined[7].

Photovoltaic (PV) interfacing inverters carries the idea of virtual harmonic damping impedance supported by numerous compensation schemes is analyzed. The solution removes the use of large electrolyte based capacitors while lesser quantity of AC-capacitors are required to equate with the buck-type AC to AC converters which unceasing g current of grid-side, which implied that no extra grid-located filters are compulsory[8]. A frequency regulating discriminating harmonic control (FA-SHC) theme is presented that might be considered for grid linked inverters for optimally eliminating harmonics present in current. Tentative tests had incontestable the effect of the familiarized FA-SHC structure in terms of exact frequency adaptableness and conjointly quick transient response[9][10].

\section{EXPERIMENT}

A PV Simulator has been used in the project to acquire direct current (DC) of solar energy. Then, with the help of on-grid inverter direct current is transformed to alternating current (AC) for directing to grid connected and/or electrical loads. Loads are classified into five types, that are herein incandescent, incandescent and ballast, ballast, motor and Light Emitting Diode (LED). In system, we connected solar energy from PV simulator to on-grid inverter, grid system, 
and loads at the joining point. Observed results were noted by oscilloscope to keep voltage and current waveforms of the system at the node point, and using Power Quality Analyzer to keep electrical parameters and harmonics as shown in Figure 1.

In accordance to the power of load, solar power is directed towards each load
1) To incandescent loads of $480 \mathrm{~W}$

2) to ballasts of $800 \mathrm{~W}$,

3) to incandescent and ballast loads of $950 \mathrm{~W}$,

4) to the LED lamps of $300 \mathrm{~W}$ and,

5) to motor of 200 watts.

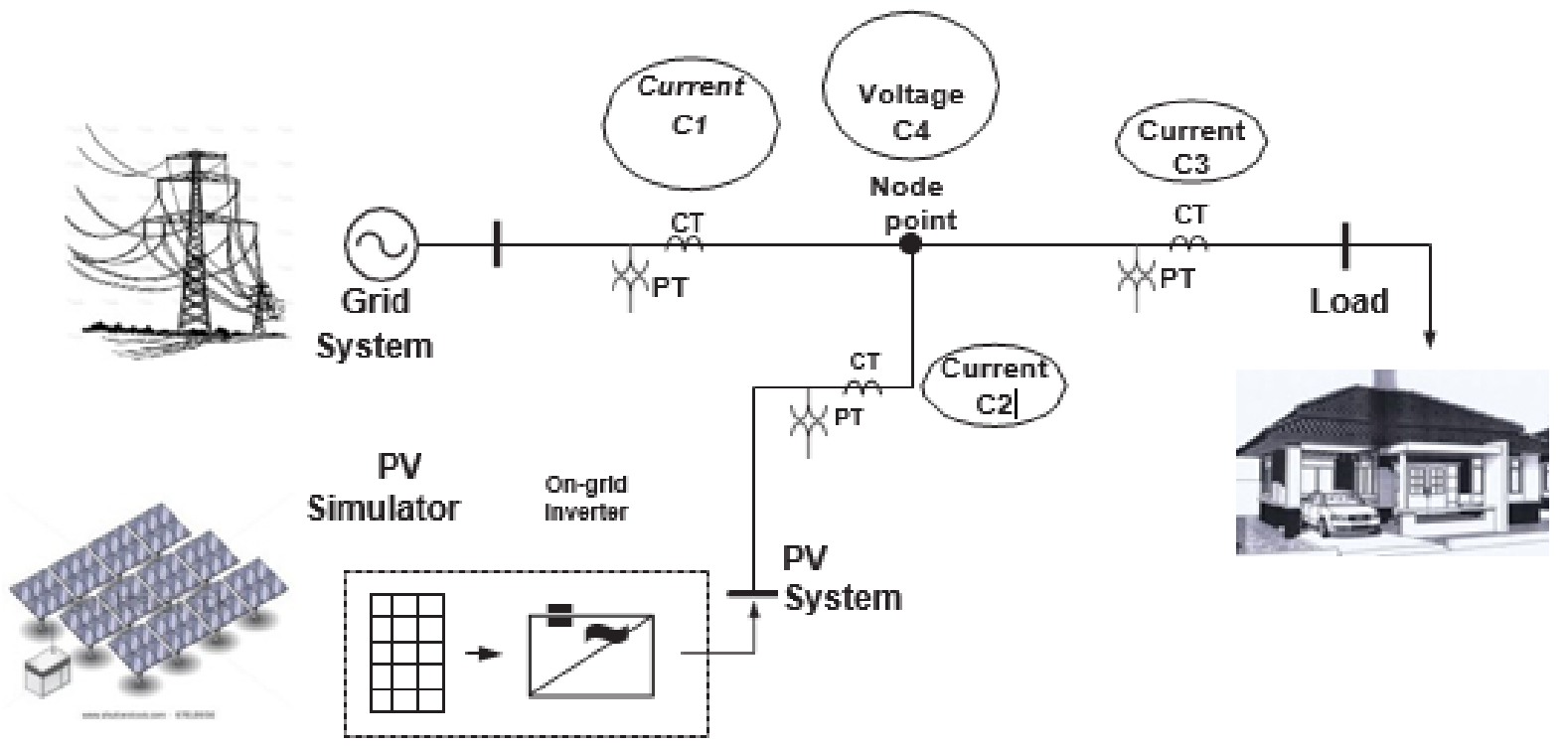

Figure 1 Overview of analysis

Current harmonic when PV generates $0 \mathrm{~W}, 100 \mathrm{~W}, 500 \mathrm{~W}, 1000 \mathrm{~W}$, and $3000 \mathrm{~W}$

120

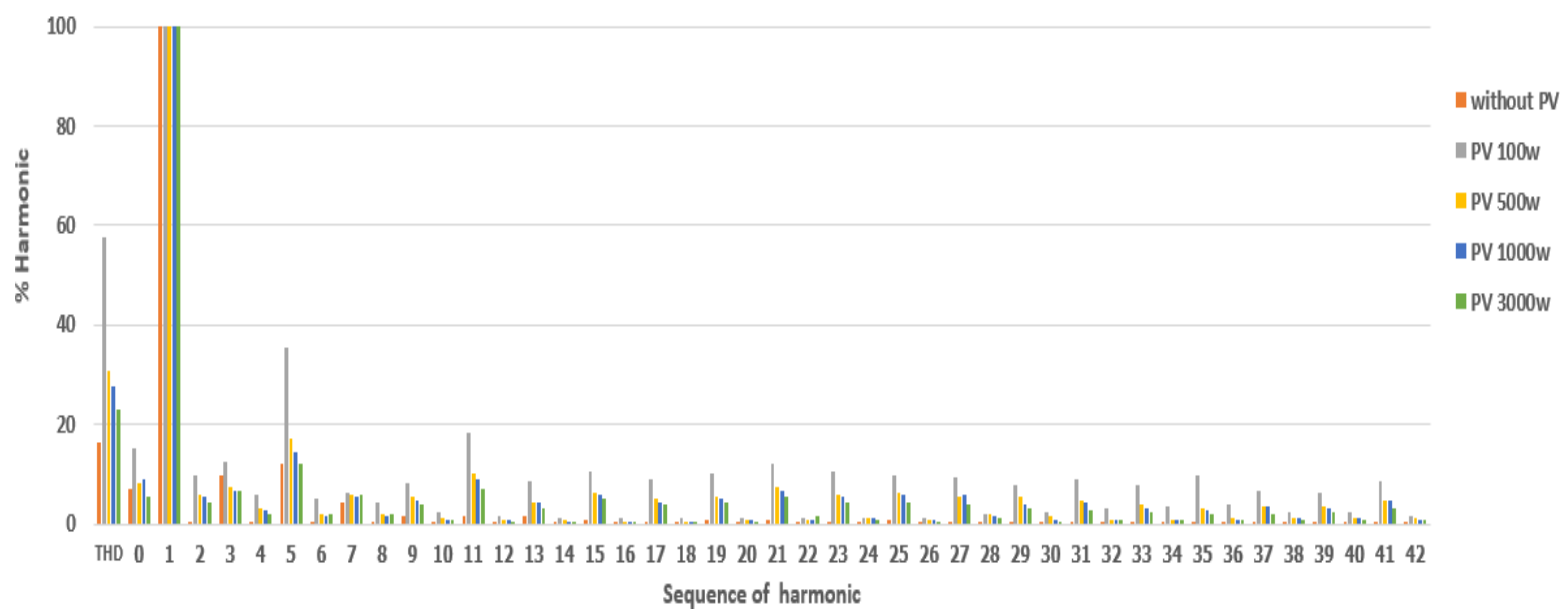

Figure 2 Current having harmonic content after PV produces Zero watt, Hundred watts, Five-hundred watts, Thousand watts, and Three-hundred watts

\section{RESULT}

Outcomes demonstrates that the system learning comprises two conditions. Initial, , loads gather power from the grid and produce harmonics that goes back to the grid when the PV based system doesn't provide power to linked node. Thus, harmonics throughout this condition are loadharmonics. Second is when the PV based system supply power to linked nodes. Throughout this learning, it's in the key thought about two configurations: including and excluding PV based system, to look at the harmonics formed in the system. Mentioned 2 cases, the voltage having harmonics are calculated at the linking node zone unit each low whereas current having harmonics are more while the $\mathrm{PV}$ produces extreme electrical wattage power in the system but the voltage having harmonics are static. However the current having harmonics are more, condition based on the category of load and existing power supply. A non-linear load having active element like light emitting diode including driver would result and amplify the whole harmonics

Published By: 
present in the system. Consequently, the main attention to be paid is to the current harmonics in the load, grid system, and PV based system.

A little power to the associated inverter while PV doesn't produce energy, the percentage of current having harmonics are produced by the electrical inverter in individual harmonic order are exposed in Figure2. Though the harmonics produced by the grid are less than 100, it's examined that the grid-related harmonics production are also surveyed. Therefore, it appears to be accomplish that the switching devices in the grid-tie inverter are the reason for the amplification of current based harmonics. The $1^{\text {st }}$ fundamental element of current is huge while the PV produces large amount of power and the current. Contrast learning of current having harmonics in the illustrated system is separated in 2 structures that are including and excluding PV connection, computing at 3 locations (grid system, PV-system location, and load side). Total 5 types of load are considered that are taken in the test, includes ballast, incandescent load, motor, incandescent load having ballast, and light emitting diode (LED) lamp.

Because the power is accepted from the mentioned grid for the system association confirmation, Thus inverter acts like an electrical load; hereafter, there's little amount of current directing from the grid towards the electrical inverter. Although PV produces one hundred Watts, entire current harmonics are exaggerated, more particularly the fifth and eleventh orders of harmonics, then PV process is moved to five hundred Watts, thousand Watts, and threethousand Watts, in the respective order. The first contrast is made with incandescent taken as a load. When PV did not produce power, The percentage of current having harmonics in the third, fifth, and seventh orders are $09.64 \%, \mathbf{1 1 . 9 3 \%}$, and $\mathbf{0 7 . 0 9 \%}$ in the respective order, and THD (total harmonics distortion) is $\mathbf{1 6 . 9 2 \%}$ measured at PV based system location while the grid and location of load are relatively minor amount since there is a lot of power moved from the grid side to the load location as compare to the electrical inverter as shown in Figure7. After the energy produced by the PV, current having harmonics at load location are same. Current having complete harmonics of the grid and PV based system are enlarged, and dramatic amplification in fifth and eleventh orders.

Current harmonic of Incandescent

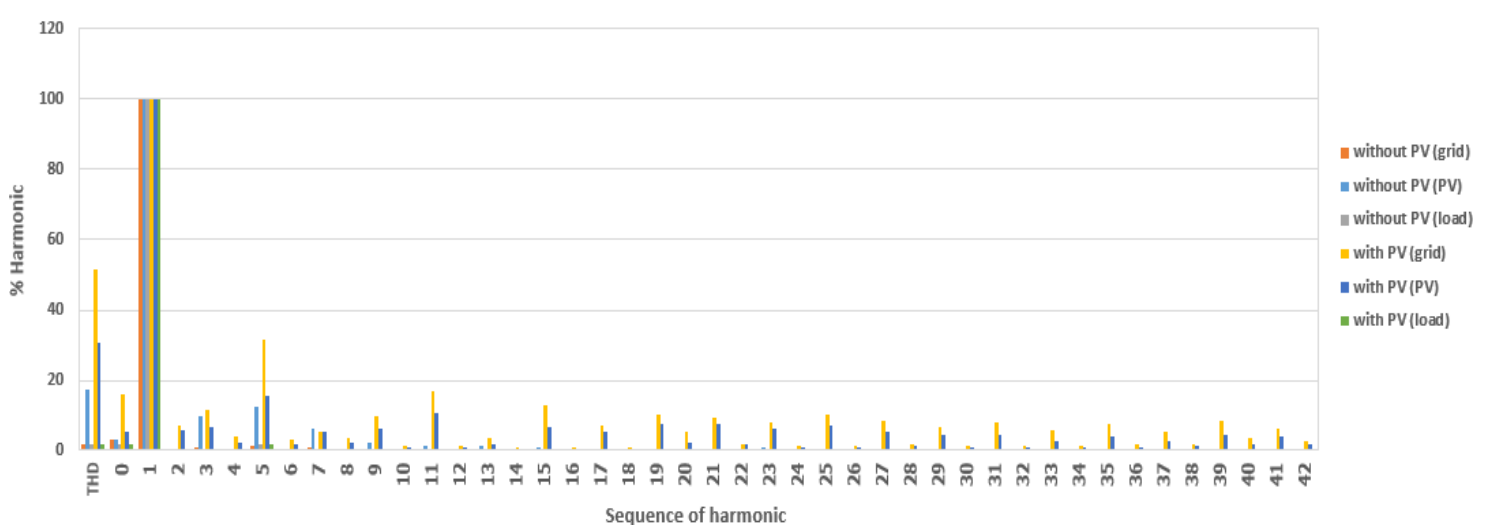

Figure 7 Current harmonics with incandescent loads when PV generates or doesn't generate solar power 


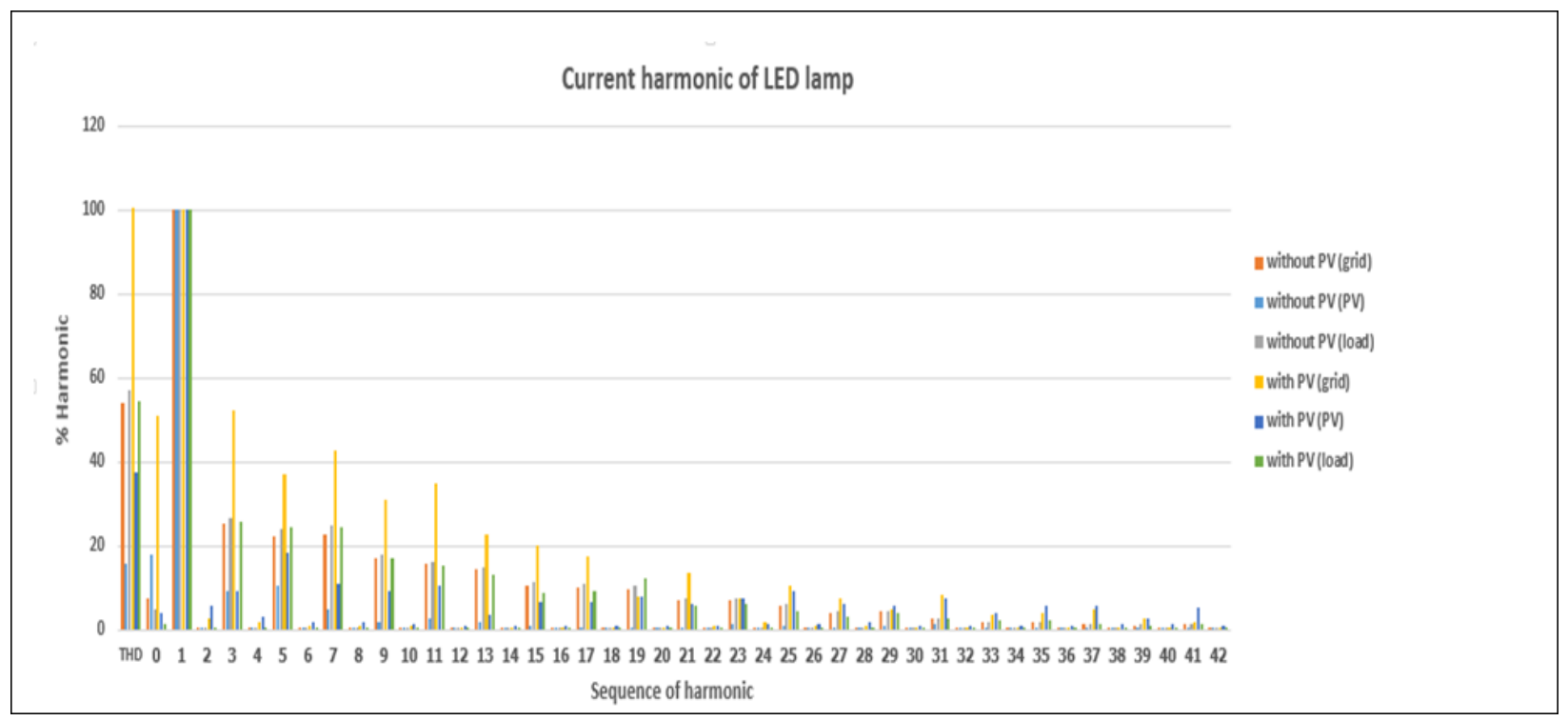

Figure 8 Current harmonics with LED loads when PV generates or doesn't generate solar energy

The second contrast is made is ballasts. The percentage of harmonics of current when PV didn't produce power in third, fifth and seventh orders are $09.5 \%, 02.71 \%$, and $\mathbf{0 1 . 1 0 \%}$ in the respective order, considered at load the location. In PV based system location, harmonics of current present at third, fifth, seventh, ninth and eleventh orders are $8.70 \%, 11.33 \%, 5.7 \%, 2.20 \%$, and $2.30 \%$ in the respective order. The current having harmonics are calculated at load side and PV system locations influenced with the location of grid at third and fifth orders, which are $\mathbf{9 . 5 \%}$ and $3.45 \%$ in the respective order. Current having harmonics of load location side and grid location side are alike due to the reason that grid transferred great amount of current to load side than to the electrical inverter. Subsequently the energy produced by PV produced, current harmonics at grid and load position are stepped-up. Current having harmonics at PV based system location in second to tenth and eleventh orders are amplified to $4.41 \%, 5.60 \%$, $2.15 \%, 14.55 \%, 1.30 \%, 8.90 \%, 1.30 \%, 6.3 \%, 0.98 \%$, and $7.63 \%$ in the respective order. Third contrast is made for the condition incandescent with ballasts loads. The percentage of current having harmonics existing while PV isn't producing power in third, fifth and seventh orders are $08.08 \%$, $02.01 \%$, and $01.17 \%$ in the respective order considered at load location. In the PV based system location, current having harmonics at third, fifth, ninth and eleventh orders are $87.90 \%, 11.21 \%, 5.58 \%, 02.35 \%$, and $2.33 \%$ in the respective orders. Current having harmonics calculated at the grid location at third, fifth and seventh orders are $\mathbf{0 8 . 0 5}$ $\%, 02.49 \%, 01.01 \%$. Current having harmonics is extremely important than the 1 st case however fewer than the 2 nd one. After the production of energy by PV, current having harmonics at load location are alike. Current having harmonics at second, third, fourth, fifth, sixth, seventh, eighth, ninth, tenth and eleventh orders of PV based system position radically amplified to $04.08 \%, 06.17 \%, 03.05 \%$, $16.98 \%, 01.27 \%, 07.21 \%, 01.13 \%, 6.16 \%, 0.82 \%$, and $8.87 \%$ in the respective order and grid site is somewhat amplified in odd orders. Consequently, it would be accomplish that current having harmonics of presented grid side are more exaggerated from load side as compare to the PV based system side.

In the fourth condition LED was considered as load through its driver. As shown in Figure5, harmonics of current at load side position while PV isn't producing power are dissimilar to the preceding conditions and have great standards in the order third, fifth, seventh, ninth, eleventh, thirteenth, fifteenth, thirteenth, seventeenth, nineteenth, twenty first, twenty third, twenty fifth, twenty seventh, twenty ninth, thirty first, thirty third, thirty fifth, thirty seventh, thirty ninth and forty first orders were $\mathbf{2 7 . 4 6 \%}$, $23.88 \%, 24.88 \%, 18.25 \%, 16.58 \%, 15.51 \%, 11.94 \%, 11.67 \%$, $12.02 \%, 8.12 \%, 8.20 \%, 6.63 \%, 3.73 \%, 5.61 \%, 3.30 \%, 2.49 \%$, $2.39 \%, 1.57 \%, 1.31 \%$, and $01.48 \%$ in the respective order. In PV system position, current harmonics were similar to the previous cases, consisting third, fifth, seventh, ninth and eleventh orders of current harmonics. It's shown in figure8 that current harmonics associated with the LED load are larger than other conditions. Afterward PV producing power is shown in Figure 6, current harmonics of load side were same. Harmonics of current of PV based system location at second, third, fourth, fifth, sixth, seventh, eighth, ninth, tenth and eleventh orders are in drastic way amplified to 05 . $56 \%, 8.97 \%, 2.96 \%, 19.00 \%, 2.05 \%, 10.83 \%, 2.07 \%, 09.35 \%$, $01.47 \%$, and $11.17 \%$ in the respective order. In the grid location, present current based harmonics are extra amplified at second, third, fourth, fifth, sixth, seventh, eighth, ninth, tenth and eleventh orders to $\mathbf{3 0 1 \%}, \mathbf{5 2 . 5 1 \%}$, $2.16 \%, 40.00 \%, 1.14 \%, 42.55 \%, 1.15 \%, 30.90 \%, 0.95 \%$, and $35.01 \%$ in the respective order due to the reason that there are influences from harmonics of current of PV based system and present load. The ending condition is for a motor. The percentage of current while PV isn't producing power, third and fifth orders that are measured at load position are $03.87 \%$ and $02.85 \%$. The measured harmonics of current at third, fifth, seventh, ninth, eleventh and thirteenth orders are $7.98 \%, 10.56 \%, 6.95 \%, 2.18 \%, 3.06 \%$, and $01.39 \%$ in the respective orders. Grid current harmonics at third and fifth

Published By: 
orders are $\mathbf{0 5 \%}$ and $\mathbf{2 . 0 1 \%}$. The condition is same as the third condition described above. After the energy produced by $\mathrm{PV}$, harmonic of current are same at load position. Complete harmonics related to current are slightly stepped-up at the system based on PV and grid position

\section{CONCLUSION}

The projected paper bestowed the contrast outcomes of excluding load and including various loads with excluding generation of PV and including PV-generation. The gridattached electrical inverter act like a load when PV isn't producing solar based energy the reason is power obtained from the grid is to validate the system association during the supervision of outcomes from the experiment. Current harmonics are affected by the operation of switching equipment and passive components due to low current flow of the system. The percentage of harmonics of current decreases due to increase in current harmonics within the system throughout when PV doesn't generate solar power. Concerning the contrast study of the current based harmonics in the system with diverse loads, and it's examined that maximum of the time harmonics of grid are influenced by the harmonics of load and PV system. However, harmonics present in load side has major affect than PV based system. The harmonics produced by the loads comprising resistance and inductance produce a smaller amount current harmonics as compare to capacitance one and switching load. The harmonics present in PV based system don't influence to load.

\section{REFRENCES}

1. A. Mohammad Bagher, "Types of Solar Cells and Application," Am. J. Opt. Photonics, 2016.

2. B. Parida, S. Iniyan, and R. Goic, "A review of solar photovoltaic technologies," Renewable and Sustainable Energy Reviews. 2011.

3. U. Aswathanarayana, "Solar energy," in Green Energy: Technology, Economics and Policy, 2010.

4. F. Wang, J. L. Duarte, M. A. M. Hendrix, and P. F. Ribeiro, "Modeling and analysis of grid harmonic distortion impact of aggregated DG inverters," IEEE Trans. Power Electron., 2011.

5. T. Ackermann, G. Andersson, and L. Söder, "Distributed generation: A definition," Electr. Power Syst. Res., 2001.

6. S.-W. Kang and K.-H. Kim, "Sliding mode harmonic compensation strategy for power quality improvement of a grid-connected inverter under distorted grid condition," IET Power Electron., 2015.

7. Y. Wang, X. Wang, F. Blaabjerg, and Z. Chen, "Harmonic instability assessment using state-space modeling and participation analysis in inverter-fed power systems," IEEE Trans. Ind. Electron., 2017.

8. R. J. Bravo, R. Yinger, S. Robles, and W. Tamae, "Solar PV inverter testing for model validation," in IEEE Power and Energy Society General Meeting, 2011.

9. H. Hu, Q. Shi, Z. He, J. He, and S. Gao, "Potential harmonic resonance impacts of PV inverter filters on distribution systems," IEEE Trans. Sustain. Energy, 2015.

10. Y. Deng, X. He, and Q. Liu, "Boost-type inverter-less shunt active power filter for VAR and harmonic compensation," IET Power Electron., 2013. 